\title{
Colorectal cancer demographics in Barbados
}

\author{
SAHLE GRIFFITH ${ }^{1}$, GREG PADMORE ${ }^{1}$, EMIL PHILLIPS ${ }^{1}$, SOLANGE S.K. RAMKISSOON ${ }^{2}$, \\ SIERRA MOORE ${ }^{1}$, KEISHA WALKES ${ }^{1}$, ABDELAZIZ A. GOHAR ${ }^{3}$ and SHAMIR O. CAWICH ${ }^{2}$ \\ ${ }^{1}$ Department of Surgery, Queen Elizabeth Hospital, Bridgetown, Barbados; \\ ${ }^{2}$ Department of Clinical Surgical Sciences, University of The West Indies, St. Augustine Campus, \\ St. Augustine, Trinidad and Tobago; ${ }^{3}$ South Valley University, Qena 83523, Egypt
}

Received March 5, 2021; Accepted April 26, 2021

DOI: $10.3892 / \mathrm{mi} .2021 .2$

\begin{abstract}
Barbados is an island in the Eastern Caribbean that is reported to have the 8th highest incidence of colorectal cancer (CRC) worldwide. However, these figures are based only on estimates, and there is little available epidemiological data collected from Barbadians with CRC. The present study sought to collect epidemiologic data from patients in Barbados diagnosed with CRC. This information is considered important to shape national public health policies. For this purpose, hospital admission registers at all tertiary care facilities in Barbados were retrospectively audited over a four-year period from January 1, 2014 to December 31, 2018 to identify patients who underwent operative treatment for CRC. The following data were extracted: Age, sex, ethnicity, the location of the primary tumour and tumour stage. Descriptive statistical analyses were generated using SPSS version 21.0. The results revealed that there were 97 patients with $\mathrm{CRC}$ at a mean age of 64.9 years $(\mathrm{SD} \pm 12.2)$ and a male preponderance (1.3:1). The majority (93.8\%) were from the African diaspora. Only $18.5 \%$ of diagnoses were made at (opportunistic) screening. Consequently, two thirds of the patients had advanced-stage disease at diagnosis. The disease staging of the patients was as follows: Stage $0(1 \%)$, stage I $(10.3 \%)$, stage II $(23.7 \%)$, stage III (38.1\%) and stage IV (26.8\%). Right-sided primary tumours were most common $(44.3 \%)$, followed by left-sided (41.2\%) and rectal lesions (14.4\%). Women were significantly more likely to have right-sided lesions (55 vs. $45 \%$ ) and males were more likely to have rectal lesions (77 vs. $23 \%$ ). On the whole, the present study highlights the need to implement a national screening programme in this high-risk population of African origin with a predominantly right-sided distribution of CRC primary tumours. This is reinforced by the fact that $10 \%$
\end{abstract}

Correspondence to: Professor Shamir O. Cawich, Department of Clinical Surgical Sciences, University of The West Indies, St. Augustine Campus, St. Augustine, Trinidad and Tobago

E-mail: socawich@hotmail.com

Key words: colorectal cancer, colorectal neoplasm, colorectal tumour of patients will be diagnosed before the age of 50 years with more aggressive disease.

\section{Introduction}

Barbados is a developing island state in the Eastern Caribbean that occupies an area of 166 square miles and has a population of 287,371 individuals (1). The World Health Organization (WHO) published Globocan data in 2020 suggesting that colorectal cancer (CRC) was the second most common cause of cancer-related mortality in Barbados (2). However, in that publication, the WHO also acknowledged that no country-specific data were available. Therefore, the majority of Barbadian Globocan 2020 statistics were derived 'from national mortality estimates by modelling using mortality: Incidence ratios derived from cancer registry data in neighbouring countries' (2).

While it is reasonable to base estimates on data from neighbouring countries with similar populations, it is also possible that cultural, environmental and/or genetic differences may exist in the Barbadian population. Therefore, the present study sought to collect demographic data from Barbadian patients diagnosed with CRC. These are considered important data that could shape public health policies and guide screening protocols in Barbados.

\section{Patients and methods}

Patient information. Barbados is a small independent island in the Eastern Caribbean that is classified as a high-income country in a region of predominantly middle-income economies. The Government of Barbados offers free health care to all legal residents, funded by state taxation, through a network of public health clinics distributed across the nation. When necessary, these clinics refer patients to the sole public tertiary referral centre located in the capital city of Bridgetown. All patients who are diagnosed with CRC in the government-subsidized health care delivery system are referred to this facility for definitive surgical and oncologic care. There is also a parallel private health care system in Barbados that is staffed by independent providers on a fee-for-service model. At the time of the present study, there was one private facility providing tertiary surgical and medical oncologic care for patients with $\mathrm{CRC}$ on the island of Barbados. Colonoscopies 
were available in both healthcare systems from five providers across the island.

Approval was secured from the Institutional Review Board (Caribbean Colon Cancer Initiative Review Board, CCCI/2020/12-3) to retrospectively audit hospital admission registers at both facilities over a four-year period from January 1, 2014 to December 31, 2018. Patients who underwent operative treatment for CRC over the study period were identified and their hospital records were retrieved for detailed analysis. The following data were extracted: Age, sex, ethnicity, mode of diagnosis, location of the primary and American Joint Committee on Cancer (AJCC) stage. Right-sided primary tumours were defined as those that arose in the cecum, ascending colon, hepatic flexure and/or transverse colon (3). Left-sided primary tumours were defined as those that originated from the splenic flexure, descending colon and/or sigmoid colon (3). Rectal lesions were considered separately.

Statistical analysis. Descriptive statistical analyses of patient data were generated using SPSS version 21.0 (SPSS, Inc.). Descriptive analyses for the dataset were performed using the Chi-squared test and a P-value $<0.05$ was considered to indicate a statistically significant difference.

\section{Results}

Over the study period, 97 patients were diagnosed with CRC at a mean overall age of 64.9 years $(\mathrm{SD} \pm 12.2)$ at the time of diagnosis. There was a male preponderance, with 54 males at an average age of 64.5 years (median, 64; mode, 64; $\mathrm{SD} \pm 11.3$ ) and 43 females at an average age of 65.4 years (median, 63; mode, 58; $\mathrm{SD} \pm 13.5$ ) (Table I). The majority (93.8\%) of patients diagnosed with CRC in this population were of Afro-Caribbean ethnicity. The prevalence of CRC was examined according to age. The incidence of CRC increased with age, and peaked in the seventh decade of life, as illustrated in Fig. 1.

At the time of the study, there was no organized national screening programme in Barbados, although faecal occult blood testing and colonoscopies were available ad hoc from public and private facilities. A few doctors practiced opportunistic screening with faecal occult blood testing and/or colonoscopy. However, the majority of patients who were diagnosed with CRC over the study period were diagnosed upon investigational colonoscopy after they presented with symptoms. Only $15(15.5 \%)$ of patients had their diagnoses made at opportunistic screening and $82(84.5 \%)$ were diagnosed after developing symptoms suggestive of CRC.

When the location of the primary tumour was evaluated, right-sided lesions were found to be the most prevalent (Fig. 2). The most common location for a CRC primary tumour was the right side $(44.3 \%)$ followed by left-sided lesions $(41.2 \%)$ and then those in the rectum (14.4\%).

When the distribution of CRC was examined according to sex, a statistically significant association between sex and the location of the primary tumour was noted (Fig. 3). Females were significantly more likely to have right-sided lesions (55 vs. 45\%, $\mathrm{P}<0.04)$ and males were more likely to have a rectal primary tumour ( 77 vs. $23 \%$; $\mathrm{P}=0.023$ ). At the time of diagnosis, two thirds of the patients already had locally advanced or metastatic CRC upon presentation, as illustrated in Fig. 4.

\section{Discussion}

Colorectal cancer is the third most common type of cancer globally (4) and this is mirrored in Barbados. The Barbadian National Cancer Registry (5) documented that CRC accounted for $15 \%$ of all cancer diagnoses on the island, rendering it the third commonest cancer in Barbados, following prostate and breast cancers, respectively.

Using the estimated age standardized incidence rate of 30.3 per 100,000 individuals published in the WHO Globocan statistics (2), the American Institute for Cancer Research (6) ranked Barbados and Japan equally for the 8th highest rate of CRC worldwide. In fact, Barbados was the only Caribbean country to be ranked in the list of the top 25 nations with the highest CRC incidence worldwide (6). Although the incidence of CRC in Barbados is high, published research on epidemiological patterns and demographics in this population is limited. The present study only encountered two existing publications reporting on CRC in Barbados (5,7).

The majority of research reports a predilection for CRC occurring in males (8). This was also the pattern observed in Barbados (1.3:1). International data indicate that males have significantly more cancer-related deaths than females $(9,10)$ and a significantly lower overall survival $(9,11,12)$. Of note, the other Caribbean islands have reported different patterns, with published data from Jamaica $(13,14)$, Trinidad and Tobago (15) and an older Barbadian study (7), all reflecting a female predilection. The only other Caribbean nation that reported a male preponderance was Martinique (16).

There is consensus that the incidence of CRC increases with age (8). This pattern was also observed in Barbados, with a peak incidence in the 7 th decade of life. This was similar in other Caribbean populations (13-16). It was notable that $10.3 \%$ of CRC cases diagnosed in Barbados were made in individuals between 30 and 49 years of age at the time of diagnosis. It is important to acknowledge this finding as some researchers have established a strong association between early age at diagnosis, higher disease stages and lower survival rates $(17,18)$. Gabriel et al (17) examined a cohort of 670,030 individuals with CRC and reported that patients who were younger than 50 years of age at the time of diagnosis had a statistically significant increase in the proportion of stage III (22.7 vs. $28.6 \%$ ) and stage IV (25.5 vs. $14.3 \%)$ disease compared with older patients. The patients younger than 50 years at diagnosis also had a greater proportion of poor prognosticators (high tumour grade, lympho-vascular invasion, perineural invasion and elevated carcinoembryonic antigen levels), as well as a worse overall survival (17). While it is uncommon for patients to be diagnosed with CRC at this age, it is an important public health message that 1 in every 10 Barbadians with CRC will be diagnosed between 30 and 49 years of age.

Although the incidence of CRC in sub-Saharan Africa is low (4 per 100,000 individuals), there is existing data establishing that individuals from the African diaspora have a greater incidence of CRC $(19,20)$, an increased association with KRAS mutations $(18,21)$ and more aggressive tumour biology $(17,18,22,23)$. It has been suggested that these differences are linked to a combination of factors that include genetic predispositions, environmental influences, lifestyle patterns and dietary factors. With that in mind, it is important 
Table I. Demographics of the patients with colorectal cancer in the present study.

\begin{tabular}{lcc}
\hline Parameter & $\begin{array}{c}\text { No. of } \\
\text { patients (n=97) }\end{array}$ & Percentage \\
\hline Mean age \pm SD (years) & $64.9+12.2$ & - \\
Sex & & \\
$\quad$ Male & 54 & 55.7 \\
Female & 43 & 44.3 \\
Mode of diagnosis & & \\
Screening detected & 15 & 15.5 \\
Symptomatology present & 82 & 84.5 \\
Location of primary tumour & & \\
Right side & 43 & 44.3 \\
Left side & 40 & 41.2 \\
Rectum & 14 & 14.4 \\
American Joint Committee & & \\
on Cancer Stage & & \\
0 & 1 & \\
I & 10 & \\
II & 23 \\
III & 37 \\
IV & 26 \\
\hline
\end{tabular}

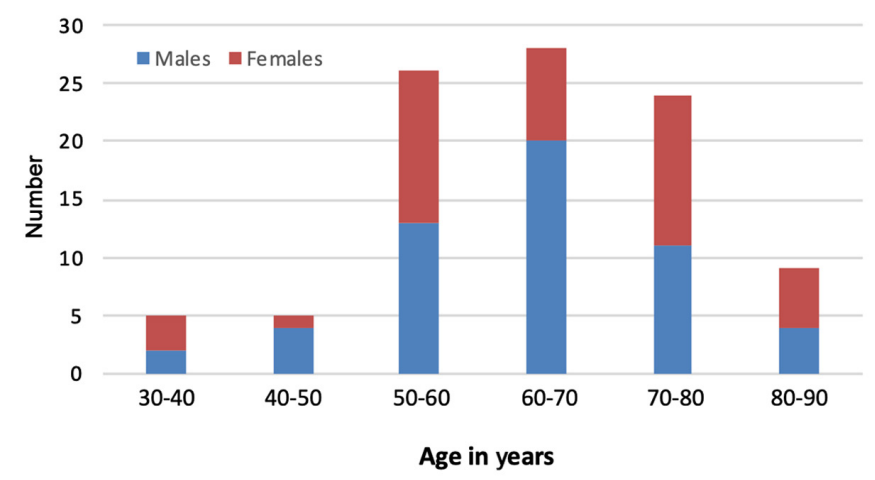

Figure 1. Distribution of colorectal cancer according to age in decades.

to acknowledge that $94 \%$ of individuals with CRC in Barbados were from the African diaspora. There are also data to indicate that there is an increase in cancer-related mortality in individuals of African descent, a lower socio-economic status and lower educational levels $(17,18,22)$. The debate continues on whether this is due to a lack of screening, inequity in access to oncology care, socioeconomic factors or genuine differences in tumour biology. At the very least, Barbadians must be educated about these differences, as $92.4 \%$ of the nation is from the African diaspora (1).

It is currently accepted that there are fundamental clinical differences based on the geographic origin of the CRC primary tumour (24). There is consensus on the definition of geographic origin of the primary $(3,24)$. The standardized definition of a right-sided CRC is one that originates in the caecum, ascending colon, hepatic flexure and/or transverse

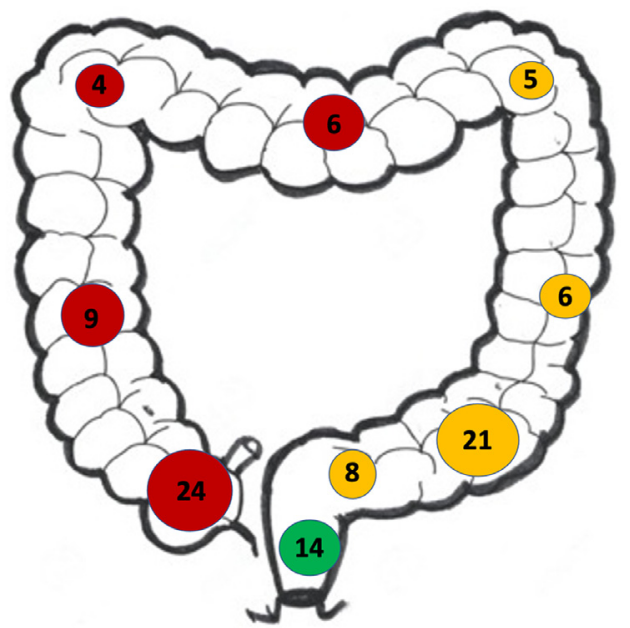

Figure 2. Distribution of colorectal cancer primaries throughout the colon. In this population, right-sided lesions (red) were more common than left-sided primaries (yellow) and rectal primaries (green).

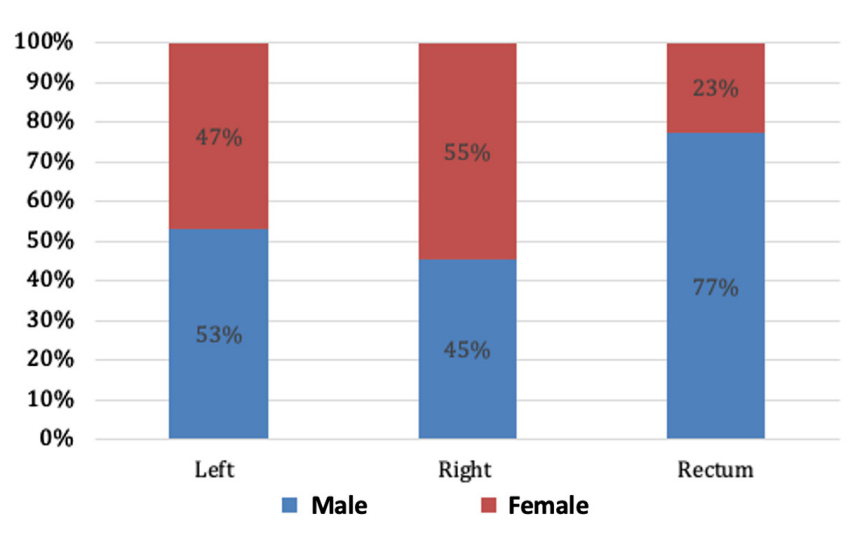

Figure 3. Analysis of the distribution of colorectal cancer primary tumours according to sex. Females were significantly more likely to have right-sided lesions ( 55 vs. $45 \%, \mathrm{P}<0.04)$ and males were more likely to have a rectal primary tumour ( 77 vs. $23 \% ; \mathrm{P}=0.023$ ).

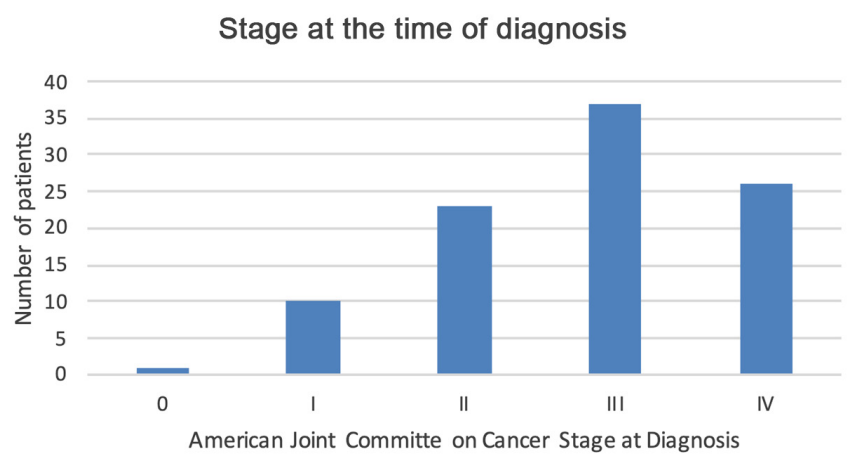

Figure 4. Distribution of the American Joint Committee of Cancer Stage at the time of diagnosis.

colon (3). Moreover, the standardized definition of a left-sided lesion is that arises from the splenic flexure, descending and/or sigmoid colon (3). Different onco-genetic pathways are involved, where right-sided CRCs have a high association with microsatellite instability. Consequently, right-sided CRC tends to present late, with non-specific symptoms (15), 
a higher cancer-related mortality $(9,12,18,25,26)$ and worse overall survival statistics $(18,27)$. These data have significant implications on the present study, as it was shown that the predominant pattern was right-sided disease in $44.3 \%$ of Barbadian patients. In a previous study, Zbar et al (7) also reported a significant right-sided shift over two decades in Barbadian patients, without a decline in left-sided primaries. A right-shift was also observed in other Caribbean nations, with McFarlane et al (13) reporting right-sided lesions in $28.5 \%$ of Jamaican patients and Joachim et al (16) reporting right-sided lesions in $26.3 \%$ of patients in Martinique.

Only one study from the Caribbean suggested a left-side predominant pattern. Rampersad et al (15) examined 118 resected specimens in Trinidad and Tobago, and reported a predominance of left-sided lesions. However, in that study, the authors assigned rectal tumours as left-sided lesions, contrary to most definitions. They reported that right-sided lesions, which they defined as those 'found in the ascending colon, including the caecum, and up to the proximal half of the transverse colon', accounted for $27 \%$ of all CRC primary tumours. These were similar to the figures reported by McFarlane et al (13) (28.5\%) and Joachim et al (16) (26.3\%). The figures were generally lower than those observed in Barbadians, although this was expected since Barbados was the only country to be ranked in the list of the top 25 nations with the highest CRC incidence worldwide (6).

The present study demonstrated that Barbadian females were statistically more likely to develop right-sided lesions than males. This is in accordance with established epidemiologic patterns in international studies $(9,12,25,27)$. This is an important point to note since right-sided lesions tend to have a more aggressive behaviour $(9,12,25,26)$ and worse survival statistics $(18,27)$.

In the present study, less than one in every seven patients had their diagnoses made at opportunistic screening. Therefore, it was not surprising that the majority of our patients presented with advanced stage III $(38.1 \%)$ or stage IV $(26.8 \%)$ disease. In addition, the knowledge that $10 \%$ of individuals will be diagnosed prior to the age of 50 years, and that these patients tend to have a worse disease course, draws attention to the urgent need to implement national screening programmes. A number of authorities have advocated screening to aid in early detection and treatment to reduce the morbidity and mortality associated with CRC. The Pan American Health Organization endorsed screening programmes for Latin American and the Caribbean 'with tests that include flexible sigmoidoscopy or colonoscopy' (28). However, policy makers may consider modifying this in Barbados, since screening sigmoidoscopy would have missed the right-sided CRC primaries in this population $(44.3 \%)$.

There are certain limitations to the present study which should be noted. One limitation was that the study methodology only allowed the collection of data from patients undergoing surgery for CRC. Data from patients with early-stage CRC treated endoscopically and those with stage IV CRC who were not amenable to surgical treatment would not be included in the data collection.

A second limitation to the present study was that immunohistochemical and molecular predictive biomarkers for CRC were not evaluated. It is estimated that genetic factors, such as mutations in the mis-match repair (MMR), adenomatous polyposis coli (APC) and MUTYH genes contribute to the development of CRC in as much as $35 \%$ of patients (18) and the mutations are most common in individuals from the African diaspora (18,29-31). The APC gene mutations allow the transcription factor $\beta$-catenin to act unopposed, leading to the overactivation of stem cells to form an adenomatous polyp (18). When other cancer driver gene mutations are acquired, such as KRAS, SMADs and p53, there is progression to invasive cancer (18). The MMR genes, such as MLH1, MSH2, MSH6 and PMS2 remove bases that were improperly incorporated into DNA during replication $(18,31)$. The $M U T Y H$ protein identifies mis-matched guanine/adenine pairs in DNA and initiates a repair event to insert a cytosine base opposite the oxidized guanine base. In the event of MUTYH gene mutations, DNA repair is defective and contributes to hereditary CRC (18). When these co-exist with microsatellite instability there is increased predisposition for changes in repeat sequence length in tumour DNA, leading to more aggressive, high-grade, poorly-differentiated, signet-ring phenotype tumours (18). While microsatellite instability occurs in $15 \%$ of the general population of persons with CRC (18), it is more common in individuals from the African diaspora (31-33). These markers were not available for evaluation in the present study; however, these may form the basis of further research in the Barbadian population.

In conclusion, the present study highlights the need to implement a national screening programme in this high-risk black population with predominantly right-sided distribution of CRC primary tumours. This is reinforced by the fact that $10 \%$ of individuals will be diagnosed before the age of 50 years, with more aggressive disease.

\section{Acknowledgements}

Not applicable.

\section{Funding}

No funding was received.

\section{Availability of data and materials}

The datasets used and/or analysed during the current study are available from the corresponding author on reasonable request.

\section{Authors' contributions}

SG and SOC designed and coordinated the study. SG, GP, EP, KW, SSKR, SM and AAG performed the analyses, and acquired and analysed the data. SG, SSKR and SOC interpreted the data. SG and SOC wrote the manuscript. SG, SOC and GP confirm the authenticity of all the raw data. All authors have read and approved the final version of the article.

\section{Ethics approval and consent to participate}

Study approval was secured from the Institutional Review Board (Caribbean Colon Cancer Initiative Review Board, 
CCCI/2020/12-3) to retrospectively audit hospital admission registers at both facilities over a four-year period from January 1, 2014 to December 31, 2018.

\section{Patient consent for publication}

Not applicable.

\section{Competing interests}

The authors declare that they have no competing interests.

\section{References}

1. Government of Barbados: Demographics of the Nation. https://www.gov.bb/Visit-Barbados/demographics. Accessed January 15, 2021.

2. World Health Organization (WHO): Globocan Statistics 2020. WHO,Geneva, 2020.https://gco.iarc.fr/today/data/factsheets/popu lations/52-barbados-fact-sheets.pdf. Accessed January 30, 2021.

3. Mukund K, Syulyukina N, Ramamoorthy S and Subramaniam S: Right and left-sided colon cancers-specificity of molecular mechanisms in tumorigenesis and progression. BMC Cancer 20 $317,2020$.

4. Bray F, Ferlay J, Soerjomataram I, Siegel RL, Torre LA and Jemal A: Global cancer statistics 2018: GLOBOCAN estimates of incidence and mortality worldwide for 36 cancers in 185 countries. CA Cancer J Clin 68: 394-424, 2018.

5. Rose AMC, Campbell JM, Forde SA, Hambleton I, Greaves N and Prussia P: Cancer in Barbados 2013: Annual report of the BNR-Cancer. The George Alleyne Chronic Disease Research Centre, the University of the West Indies, St Michael, Barbados. http://www.bnr.org.bb/cms/index.php?option=com_remository\& Itemid $=61 \&$ func $=$ startdown\&id=45. Accessed March 1, 2021.

6. World Cancer Research Fund (WCRF), American Institute for Cancer Research: Colorectal cancer statistics. WCRF International, London, 2019. https://www.wcrf.org/dietandcancer/cancer-trends/colorectal-cancer-statistics. Accessed January 4, 2021.

7. Zbar AP, Inniss M, Prussia PR and Shenoy R: The changing distribution of colorectal cancer in Barbados: 1985-2004. Dis Colon Rectum 50: 1215-1222, 2001

8. Brenner H, Kloor M and Pox CP: Colorectal cancer. Lancet 383: $1490-1502,2014$

9. Yang Y, Wang G, He J, Ren S, Wu F, Zhang J and Wang F: Gender differences in colorectal cancer survival: A meta-analysis. Int J Cancer 141: 1942-1949, 2017.

10. Paulson EC, Wirtalla C, Armstrong K and Mahmoud NJ: Gender influences treatment and survival in colorectal cancer surgery. Dis Colon Rectum 52: 1982-1991, 2009.

11. Berger MD, Yang D, Sunakawa Y, Zhang W, Ning Y, Matsusaka S, Okazaki S, Miyamoto Y, Suenaga M, Schirripa M, et al: Impact of sex, age, and ethnicity/race on the survival of patients with rectal cancer in the United States from 1988 to 2012. Oncotarget 7 : 53668-53678, 2016.

12. Press OA, Zhang W, Gordon MA, Yang D, Lurje G, Iqbal S, El-Khoueiry A and Lenz HJ: Gender-related survival differences associated with EGFR polymorphisms in metastatic colon cancer. Cancer Res 68: 3037-3042, 2008.

13. McFarlane MEC, Rhoden A, Fletcher PR and Carpenter R: Cancer of the colon and rectum in a Jamaican population: Diagnostic implications of the changing frequency and subsite distribution. West Ind Med J 53: 170-173, 2004.

14. Plummer JM, Leake PA, Ferron-Boothe D, Roberts PO, Mitchell DI and McFarlane MEC: Colorectal cancer survival in Jamaica. Ann Med Surg (Lond) 6: 26-29, 2016.

15. Rampersad MK, Mohammed SR and Jurawan R: A Single centre retrospective review of colorectal cancer in Trinidad over a 3-year period. Gastroent Hepatol Open Access 8: 264-268, 2017.
16. Joachim C, Veronique-Baudin J, Razanakaivo M, Macni J, Pomier A, Dorival MJ, Smith-Ravin J, Piere-Lois O and Escarmant P: Trends in colorectal cancer in the Caribbean: A population-based study in Martinique, 1982-2011. Rev Epidemiol Sante Publique 65: 181-188, 2017.

17. Gabriel E, Attwood K, Al-Sukhni E, Erwin D, Boland P and Nurkin S: Age-related rates of colorectal cancer and the factors associated with overall survival. J Gastrointest Oncol 9: 96-110, 2018.

18. Augustus GJ and Ellis NA: Colorectal cancer disparity in African Americans: Risk factors and carcinogenic mechanisms. Am J Pathol 188: 291-303, 2018.

19. American Cancer Society: Cancer Facts \& Figure 2019. American Cancer Society, Atlanta, 2019. https://www.cancer.org/content/dam/ cancer-org/research/cancer-facts-and-statistics/annual-cancer-factsand-figures/2019/cancer-facts-and-figures-2019.pdf.

20. Simon MS, Thomson CA, Pettijohn E, Kato I, Rodabough RJ, Lane D, Hubbel FA, O'Sullivan MJ, Adams-Campbell L, Mouton CP, et al: Racial differences in colorectal cancer incidence and mortality in the Women's Health Initiative. Cancer Epidemiol Biomarkers Prev 20: 1368-1378, 2019.

21. Staudacher JJ, Yazici C, Bul V, Zeidan J, Khalid A, Xia Y, Krett $\mathrm{N}$ and Jung B: Increased Frequency of KRAS Mutations in African Americans Compared with Caucasians in sporadic colorectal cancer. Clin Transl Gastroenterol 8: e124, 2017.

22. Ollberding NJ, Nomura AMY, Wilkens LR, Henderson BE and Kolonel LN: Racial/ethnic differences in colorectal cancer risk: The multiethnic cohort study. Int J cancer 129: 1899-1906, 2011.

23. Askari A, Nachiappan S, Currie A, Latchford A, Stebbing J, Bottle A, Athanasiou T and Faiz O: The relationship between ethnicity, social deprivation and late presentation of colorectal cancer. Cancer Epidemiol 47: 88-93, 2017.

24. Baran B, Mert Ozupek N, Yerli Tetik N, Acar E, Bekcioglu O and Baskin Y: Difference between left-sided and right-sided colorectal cancer: A focused review of literature. Gastroenterol Res 11: 264-273, 2018

25. Hansen IO and Jess PM: Possible better long-term survival in left versus right-sided colon cancer-a systematic review. Dan Med J 59: A4444, 2012

26. Kim SE, Paik HY, Yoon H, Lee JE, Kim N and Sung MK: Sex and gender-specific disparities in colorectal cancer risk. World J Gastroenterol 21: 5167-5175, 2015.

27. Elsaleh H, Joseph D, Grieu F, Zeps N, Spry N and Lacopetta B: Association of tumour site and sex with survival benefit from adjuvant chemotherapy in colorectal cancer. Lancet 355: 1745-1750, 2000.

28. Pan American Health Organization (PAHO): Colorectal Cancer Screening in the Americas. Situation and Challenges. PAHO, Washington, DC, 2016. https://www.paho.org/hq/dmdocuments/2016/Colorectal-Cancer-Screening-Landscape-English.pdf.

29. Guindalini RS, Win AK, Gulden C, Lindor NM, Newcomb PA, Haile RW, Raymond V, Stoffel E, Hall M, Llor X, et al: Mutation spectrum and risk of colorectal cancer in African American families with Lynch syndrome. Gastroenterol 149: 1446-1453, 2015.

30. Weber TK, Chin HM, Rodriguez-Bigas M, Keitz B, Gilligan R, O'Malley L, Urf E, Diba N, Pazik J and Petrelli NJ: Novel hMLH1 and hMSH2 germline mutations in African Americans with colorectal cancer. JAMA 281: 2316-2320, 1991.

31. Inra JA, Steyerberg EW, Grover S, McFarland A, Syngal S and Kastrinos F: Racial variation in frequency and phenotypes of APC and MUTYH mutations in 6,169 individuals undergoing genetic testing. Genet Med 17: 815-821, 2017.

32. Ashktorab H, Smoot DT, Carethers JM, Rahmanian M, Kittles R, Vosganian G, Doura M, Nidhiry E, Naab T, Momen B, et al: High incidence of microsatellite instability in colorectal cancer from African Americans. Clin Cancer Res 9: 1112-1117, 2003.

33. Ashktorab H, Smoot DT, Farzanmehr H, Fidelia-Lambert M, Momen B, Hylind L, Iacosozio-Dononue C, Carethers JM, Goel A, Boland CR and Giardiello FM: Clinicopathological features and microsatellite instability (MSI) in colorectal cancers from African Americans. Int J Cancer 116: 914-919, 2005.

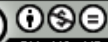

This work is licensed under a Creative Commons Attribution-NonCommercial-NoDerivatives 4.0 International (CC BY-NC-ND 4.0) License. 